\title{
$\mathrm{EM}$ 시뮬레이션을 기반으로 한 트라이섹션 대역 통과 여파기의 새로운 설계
}

\section{A New Design of Trisection Band-Pass Filter Based on Electromagnetic Simulation}

\author{
김 소 수.염 경 환* \\ So-Su Kim · Kyung-Whan Yeom* \\ 요 약
}

본 논문에서는 중심 주파수 $2.44 \mathrm{GHz}$, 상대 대역폭 $5 \%$, 반사 손실 $18 \mathrm{~dB}$, 전달 영점 주파수 $2.63 \mathrm{GHz}$ 을 갖는 트라이섹션 대역 통과 여파기를 다중 포트 EM(ElectroMagnetic) 시뮬레이션을 이용한 설계를 보인다. 교차 결합 (cross-coupling)이 포함된 트라이섹션 여파기 결합 행렬을 계산하고, 여파기를 무손실 2-포트 회로로 변환하여 기준형 등가 회로를 결정한다. 여파기 설계를 위해 개별 공진기로 분해한 후 다중 포트 EM 시뮬레이션으로 얻 어진 Y-파라미터에서 J-인버터와 서셉턴스 기울기를 기준형 등가 회로의 J-인버터 및 서셉턴스 기울기에 정합하 여 여파기 설계 치수들을 결정하게 된다. 결정된 물리적 치수로 구성된 여파기는 결합 행렬에서 고려하지 않은 결합으로 주파수 응답 특성이 기준형 등가 회로에 비해 다소 차이를 보이게 된다. 여파기 응답 특성의 최적화를 위해 초기 설계 치수를 변화시켜 여파기의 $\mathrm{EM}$ 시뮬레이션 결과들을 모아 회로에서 최적화하여 최종 설계 치수 를 얻는다. 최종 설계 치수를 갖는 여파기를 제작하여 트라이섹션 여파기 설계 방법의 타당성을 검증하였다.

\begin{abstract}
In this paper, we present the trisection band-pass filter with a transmission zero at $2.63 \mathrm{GHz}$, which has a center frequency of $2.44 \mathrm{GHz}$, relative bandwidth of $5 \%$, and return loss of $18 \mathrm{~dB}$, based on a multi-port ElectroMagnetic simulation. The coupling matrix for the trisection filter is calculated and this filter is transformed into band-pass filter prototype through a lossless 2-port circuit transformation. The J-inverter values and slope parameters of each individual resonator are computed using an EM simulation Y-parameters of the filter with multi port. The dimensions of desired filter are determined by matching the computed J-inverter and susceptance slope parameters to those of the prototype band-pass filter. Undesired cross-couplings are found to occur which does not appear in the prototype trisection filter. To overcome the problem of undesired couplings, the filter was optimized to satisfy the same frequency response of prototype filter. The validity of the proposed design method was verified through the implementation of the designed and optimized filter.
\end{abstract}

Key words : EM Simulation, Band-Pass Filter, Trisection Band-Pass Filter

$$
\text { I. 서 론 } \quad \mathrm{EM}(\text { ElectroMagnetic) 시뮬레이션을 이용한 여파기 }
$$

\footnotetext{
「이 논문은 2011학년도 정부(교육과학기술부)의 재원으로 한국연구재단 연구비의 지원을 받아 수행된 연구임(2011-0003851).」 국방과학연구소(Agency for Defence Development)

*충남대학교 전파공학과(Department of Radio Science \& Engineering, Chungnam National University)

·논 문 번 호 : 20110830-095

·교 신 저 자 : 염경환(e-mail : khyeom@cnu.ac.kr)

· 수정완료일자 : 2011년 11월 8일
} 
설계는 긴 해석 시간으로 인하여 과거에는 이를 직 접적으로 설계에 이용하지 못하였다. 최근 $\mathrm{PC}$ 의 발 전과 $\mathrm{EM}$ 시뮬레이터의 성능 향상으로 $\mathrm{EM}$ 해석 시 간이 단축된 바 있다. 그러나 복잡한 초고주파 회로 의 경우, 정확한 설계에는 $\mathrm{EM}$ 시뮬레이션을 이용한 반복적인 설계와 상당한 계산 시간이 필요하며, 실 제적으로 직접 $\mathrm{EM}$ 최적화에 의한 여파기 설계는 한 계가 있다. 따라서 여파기 초기 설계가 중요한 요소 가 되며, 여파기 설계에 있어 적절한 초기 값이 설정 되면 최종 여파기 특성을 얻기 위한 최적화 시간을 감소시킬 수 있으며, 또한 이러한 절차에 의한 여파 기의 설계 결과는 상당히 양호하다 ${ }^{[1]}$.

최근 Swanson과 Macchiarella ${ }^{[2]}$ 는 여파기 설계 변 수의 초기값 결정과 이를 이용한 최적화 문제들을 EM 시뮬레이션을 기반으로 해결할 수 있음을 보였 다. 여파기의 물리적 치수를 결정하기 위해 여파기 의 회로 모델로부터 유도된 수식들을 이용하면 초기 값 결정에 유용하다. 그러나 여파기의 구조가 더욱 복잡해짐에 따라 여파기 설계 공식의 유도 및 여파 기로의 직접 적용이 어렵다. 이를 해결하기 위해 과 거 Dishal의 실험적 여파기 설계 방법을 $\mathrm{EM}$ 설계에 적용하여 설계하는 방법이 일반적으로 사용된다. 이 것은 여파기의 초기값을 결정하기 위해 여파기를 구 성하는 입·출력단 $\mathrm{Q}$ 와 내부공진기의 결합도를 측 정하여 치수를 결정하는 방법이다 ${ }^{[3] \sim 66]}$. 그러나 이러 한 여파기의 설계 방법은 이웃하지 않은 공진기의 부하 효과를 고려하지 못하는 단점이 있다. 이를 개 선하기 위해 Bandler와 공저자들 ${ }^{[7],[8]}$ 이 공간 맵핑(space mapping) 방법을 제안하였다. 이 방법은 설계 규 격과 초기 $\mathrm{EM}$ 설계의 불일치를 조정하는 것에 효과 적이며, $\mathrm{EM}$ 시뮬레이션에 맵핑되는 회로적인 개략 모델(coarse model)을 구성하고 개략 모델을 최적화 하여 설계하는 방법이다. 그러나 개략 모델의 구축 은 상당한 경험을 필요로 하며, 여러 가지 개략 모델 이 가능하게 되며, 또한 물리적 근거가 부족한 단점 이 있다. 따라서 공간 맵핑 방법은 여파기의 초기 설 계값을 계산하기 보다 전체적인 여파기의 최적화 설 계에 적합하다.

본 논문에서는 이와는 달리, 여파기의 적절한 위 치에 다중 포트를 삽입하고, $\mathrm{EM}$ 시뮬레이션을 수행 하여 얻어진 Y-파라미터로부터 여파기의 인버터 값
과 서셉턴스 기울기를 계산하며, 계산된 값을 기준 형(prototype)과 정합시켜 초기 설계를 완료하며, 이 와 같이 결정된 초기 설정값을 기준으로 초기 설정 값의 미소 변화에 대해 $\mathrm{EM}$ 데이터를 얻고, 이 데이 터로부터 최적화를 통하여 설계하는 새로운 방법을 제시한다. 이러한 설계 방법을 검증하기 위해 중심 주파수 $2.44 \mathrm{GHz}$, 상대대역폭 $5 \%$, 반사 손실 $18 \mathrm{~dB}$, 전달 영점 주파수 $2.63 \mathrm{GHz}$ 의 설계 규격을 설정하여 교차 결합을 갖는 트라이섹션 대역 통과 여파기를 설계하였다. 이를 바탕으로 트라이섹션 여파기를 제 작하여 새로운 여파기 설계 방법의 타당성을 보 였다.

\section{II. 트라이섹션 여파기 설계}

\section{2-1 트라이섹션 여파기}

여파기의 트라이섹션 여파기 구조는 입 · 출력수정 공진기에서 발생하는 교차 결합으로 구현된다. 그림 1(a)는 본 논문에서 제시한 EM 시뮬레이션에 기초

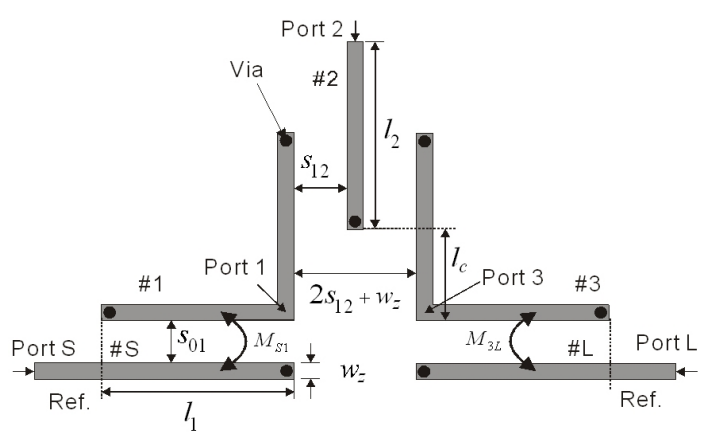

(a)

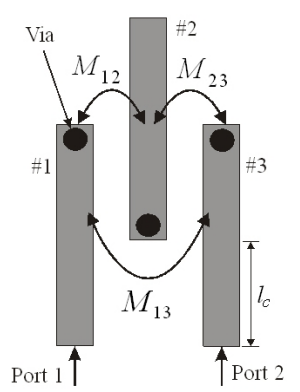

(b)

그림 1. (a) 트라이섹션 대역 통과 여파기 구조, (b) 교차 결합 중앙공진기

Fig. 1. (a) Structure of trisection band-pass filter, (b) cross coupled resonator. 
한 여파기 설계 방법을 검증할 구조로 3 개의 공진기 $(\# 1, \# 2, \# 3)$ 와 입 · 출력 포트(\#S, \#L)로 구성된다. 여 파기 설계에 필요한 충분한 교차 결합을 제공하기 위해서 입 · 출력단 공진기 $(\# 1, \# 3)$ 가 직접 교차 결합 되는 구조를 구성하기 위해 두 공진기가 평행하게 배치하였다. 또한, 불필요한 교차 결합을 최소화하 기 위해 직각으로 굽은 형태를 선택하여 교차 결합 영역을 제한하였다. 그 결과, 입출력 공진기는 결합 길이에 의해 결합되며 양 끝단이 단락된 $1 / 2$ 파장 길 이를 갖는 평행 결합 선로 구조로 구성하였다. 반면, 여파기 상하 길이를 줄이고 설계의 적합성을 위해 중앙공진기(\#2)는 입 · 출력단 공진기들(\#1,\#3)과 결 합을 위해 한쪽 끝단을 단락하고, 반대쪽은 개방하 여 $1 / 4$ 파장 길이를 갖게 하였다. 또한, 입·출력 포 트 $(\# \mathrm{~S}, \# \mathrm{~L})$ 는 $1 / 4$ 파장 길이를 갖는 단락형 결합 선로 로 입출력 공진기와 결합시켰다. 이러한 구조를 갖 는 여파기는 병렬형 대역 통과 여파기 등가 회로로 용이하게 등가화 할 수 있으며, 여기에 필요한 J-인 버터와 서셉턴스 기울기는 다중 포트 Y-파라미터를 통하여 계산될 수 있다. 그림 1(a)의 트라이섹션 여 파기는 표 1 과 같은 결합 행렬을 갖는 저역 통과 기 준형으로 주파수 변환을 통하여 변환될 수 있다. 표 1 에 보인 행렬값은 서론부에 제시한 여파기 설계 규 격을 이용하여 결정하였다 ${ }^{[1]}$.

그림 1(a)의 트라이섹션 여파기는 직접 결합(direct coupled) 여파기와는 달리 자기(self) 결합 계수(coupling coefficient) $M_{11}, M_{22}, M_{33}$ 와 교차(cross) 결합 계수 $M_{13}, M_{31}$ 를 갖게 되며, 자기 결합 계수에 의해 각 공진기의 공진 주파수 이동이 나타나고, 교차 결

표 1. 저역 통과 기준형의 결합 행렬 $\left(M_{S 1}=1.028, M_{12}\right.$ $=0.925, M_{13}=0.320, M_{11}=0.077, M_{22}=-0.325$ )

Table 1. The coupling matrix of low-pass prototype $\left(M_{S 1}=1.028, M_{12}=0.925, M_{13}=0.320, M_{11}=0.077\right.$, $\left.M_{22}=-0.325\right)$.

\begin{tabular}{|c|c|c|c|c|c|}
\hline & $S$ & 1 & 2 & 3 & $L$ \\
\hline$S$ & 0 & $M_{S 1}$ & 0 & 0 & 0 \\
\hline 1 & $M_{1 S}$ & $M_{11}$ & $M_{12}$ & $M_{13}$ & 0 \\
\hline & 0 & $M_{21}$ & $M_{22}$ & $M_{23}$ & 0 \\
\hline & 0 & $M_{31}$ & $M_{32}$ & $M_{33}$ & $M_{3 L}$ \\
\hline & 0 & 0 & 0 & $M_{L 3}$ & 0 \\
\hline
\end{tabular}

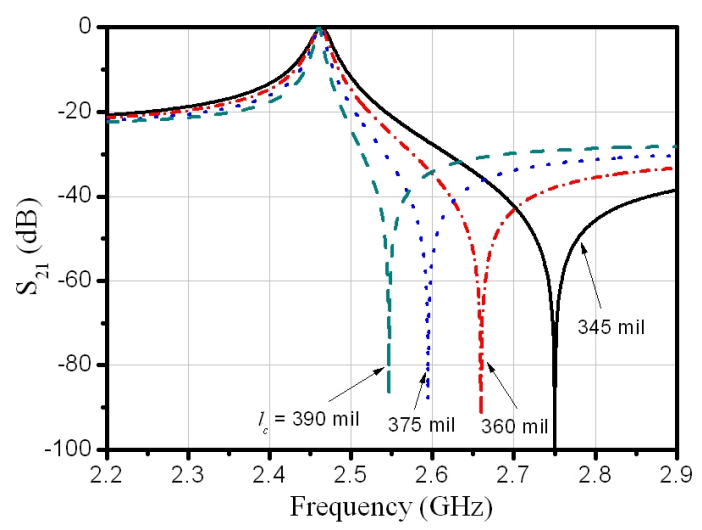

그림 2. 교차 결합을 갖는 공진기의 주파수 응답 특성

Fig. 2. Frequency response characteristics of resonator with cross coupling.

합 계수는 여파기의 전달 영점을 발생시킨다 ${ }^{[1]}$. 입 · 출력 선로 및 공진기들의 선로폭 $w_{z}$ 는 50 옴 전송선 의 선로폭과 동일하게 선정하였으며, 직접 및 교차 결합량의 변화는 공진기 사이의 간극과 중앙공진기 의 위치로 결정되게 하였다. 직접 결합되는 공진기 들의 결합량은 주로 간극 $s_{01}, s_{12}$ 로 결정되며, 교차 결합량은 $l_{c}$ 에 따라 결정되게 된다. 이를 통해 상측 대역에 전달 영점을 갖게 하였다.

그림 2는 그림 $1(\mathrm{~b})$ 의 $l_{c}$ 길이 변화에 따른 주파수 응답 특성으로 $l_{c}$ 길이가 길어질수록 교차 결합량 $M_{13}$ 이 커져 전달 영점의 주파수가 공진 주파수에 근접하게 된다. 즉, 설계하고자 하는 교차 결합량 $M_{13}$ 은 그림 1(b)의 구조로 구현 가능함을 확인하였 다. 따라서 저역 통과 기준형의 결합 행렬을 J-인버 터와 서셉턴스 기울기로 표현되는 등가 회로로 변환 할 수 있다면, 결합 행렬로 표현된 교차 결합을 갖는 트라이섹션 여파기를 설계할 수 있다.

2-2 및 2-3에서는 본 논문의 트라이섹션 여파기 설계에 필요한 다중 포트를 이용하여 J-인버터와 서 셉턴스 기울기로 표현되는 대역 통과 여파기의 기준 형 도출과 저역 통과 기준형의 결합 행렬을 정합하 는 방법을 새로이 제시하였다.

\section{2-2 트라이섹션 여파기 기준형과 결합 행렬}

그림 1(a)의 여파기는 그림 3(a)와 같은 J-인버터 등가 회로 ${ }^{[9]}$ 로 변환이 가능하다. 각각의 결합 선로들 
은 점선으로 표시된 사각형에 위치한 J-인버터로 표 현된 $J_{i, j}$ 와 J-인버터 양단의 서셉턴스 값으로 표현할 수 있다. 소스단 결합 선로의 J-인버터 값은 $J_{S, 1}$ 로 표현하였으며, 중앙공진기로의 결합을 나타내는 J인버터 값은 $J_{1,2}, J_{2,3}$ 으로 표현하였다. 또한, 교차 결 합을 갖는 J-인버터 값은 $J_{1,3}$ 으로 표현하였다. $B_{1}(\omega)$ 로 대표되는 서셉턴스는 입력단, 중앙 및 교차 결합 의 효과를 모두 합한 것으로 나타낼 수 있으며, 서셉 턴스 $B_{2}(\omega)$ 는 중앙공진기의 서셉턴스 기울기가 된 다. 그림 1(a)에서 입· 출력단, 첫 번째 공진기의 중 앙 및 중앙공진기의 개방 끝단에 포트를 삽입하면, 그림 3(a)의 J-인버터 등가 회로에서 포트를 삽입한 것으로 등가 표현 가능하다. 삽입한 포트들에 대해 다중 포트 Y-파라미터 시뮬레이션을 이용하여 J-인 버터 값, 공진 주파수 및 공진기의 서셉턴스 기울기 와 같은 여파기 설계 변수들을 추출할 수 있다. 그러 나 그림 3(a)의 등가 회로는 일반적으로 잘 알려진 그림 3(c)와 같은 대역 통과 여파기의 기준형 회로 ${ }^{[6]}$ 와 비교하였을 때, 입 - 출력단에 존재하는 $B_{S}(w)$ 와 $B_{L}(w)$ 의 서셉턴스로 인해 일반적인 대역 통과 여파 기의 기준형 회로와 차이가 발생한다. 그림 $3(\mathrm{~b})$ 는 서셉턴스를 갖는 입·출력단에 대한 대역 통과 여파 기 기준형 회로의 등가 입력단 회로를 나타내었다.

그림 3(b)의 $Y_{i n}^{\prime}$ 의 실수부와 이에 해당하는 그림 3(a)의 포트 1에서 바라본 입력 어드미턴스의 실수 부를 같도록 하여, 이를 그림 3(a)의 다중 포트 Y-파 라미터인 $y_{i j}$ 로 나타내면

$$
\frac{\left(J_{S, 1}^{e f f}\right)^{2}}{Y_{0}}=\operatorname{Re}\left(Y_{i n}^{\prime}\right)=\operatorname{Re}\left\{y_{11}-\frac{\left(y_{S 1}\right)^{2}}{y_{S S}+Y_{0}}\right\}
$$

을 얻게 된다. 따라서 실효 J-인버터 값 $J_{S, 1}^{e f f}$ 은 식 (2) 와 같이 계산할 수 있다.

$$
J_{S, 1}^{e f f}=\sqrt{Y_{0} \operatorname{Re}\left(Y_{i n}^{\prime}\right)}
$$

유사한 방법으로 두 회로의 서셉턴스 기울기를 정합하여, 첫 번째 공진기의 실효 서셉턴스 기울기 를 식 (3)과 같이 표현할 수 있다.

$$
\beta_{1}^{e f f}=\left.\frac{f_{0}}{2} \frac{\partial}{\partial f} B_{1}^{e f f}\right|_{f=f_{o}}=\left.\frac{f_{0}}{2} \frac{\partial}{\partial f} \operatorname{Im}\left(Y_{i n}^{\prime}\right)\right|_{f=f_{o}}
$$

여기서, $f_{o}$ 은 여파기의 중심 주파수이며, $\beta_{1}^{e f f}$ 는 입력

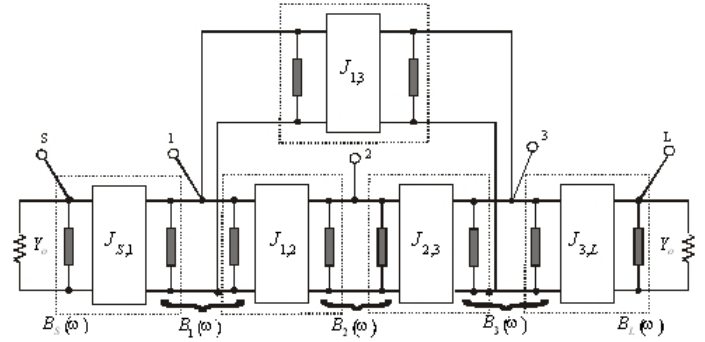

(a) J-인버터 등가 회로

(a) Equivalent circuit with J-inverter

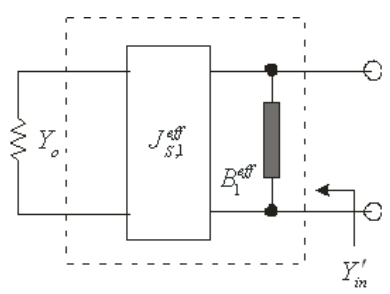

(b) 등가 J-인버터와 서셉턴스를 갖는 입력단 회로

(b) Input circuit with equivalent J-inverter and susceptance

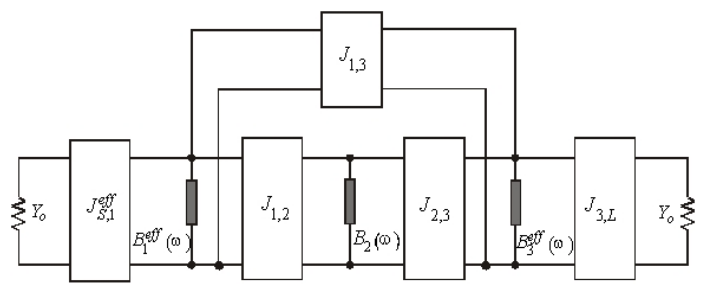

(c) 트라이섹션 여파기의 기준형

(c) Prototype of trisection filter

그림 3. 트라이섹션 여파기의 기준형 변환

Fig. 3. Prototype transformation of trisection filter.

공진기에 대한 보상된 서셉턴스 기울기를 의미한다. 입 - 출력단 이외의 서셉턴스 기울기는 식 (4-1)과 같 이 표현할 수 있으며, 인버터 값은 식 (4-2)와 같이 $\mathrm{Y}$-파라미터로부터 계산한 $y_{i j}$ 의 리액턴스 성분으로 표현할 수 있다.

$$
\begin{aligned}
& \beta_{i}=\left.\frac{f_{0}}{2} \frac{\partial\left\{\operatorname{Im}\left(y_{i i}\right)\right\}}{\partial f}\right|_{f=f_{o}} \\
& J_{i, j}=\operatorname{Im}\left(y_{i j}\right)
\end{aligned}
$$

결과적으로 기준형의 인버터 및 공진기는 다중 포트 Y-파라미터를 이용하여 그림 3(c)와 같이 기준 형으로 변환할 수 있다.

다중 포트를 갖는 여파기의 포트 $i$ 와 $j$ 사이의 결 합 계수 $k_{i, j}$ 는 앞서 얻어진 여파기 기준형의 값으로 
부터 참고문헌 [10]에 의해 식 (5), (6) 및 (7)로 나타 낼 수 있다.

$$
\begin{aligned}
& k_{i, j}=\frac{J_{i, j}}{\sqrt{\beta_{i} \beta_{j}}}(i \neq S, N \text { and } j \neq 1, L) \\
& k_{S, 1}=\frac{J_{S, 1}^{\text {eff }}}{\sqrt{Y_{o} \beta_{1}^{\text {eff }}}} \\
& k_{N, L}=\frac{J_{N, L}^{\text {eff }}}{\sqrt{Y_{o} \beta_{N}^{\text {eff }}}}
\end{aligned}
$$

여기서, $S$ 와 $L$ 은 각각 소스 노드와 부하 노드를 의 미한다. 또한, 공진 주파수 $\omega_{r, i}$ 는 식 (8)과 같이 개별 포트의 어드미턴스가 영이 되는 주파수에서 결정 된다.

$$
B_{i}\left(\omega_{r, i}\right)=\left.\operatorname{Im}\left(y_{i i}\right)\right|_{\omega=\omega_{r, i}}=0
$$

식 (5)에서 식 (8)까지는 EM 시뮬레이션된 다중 포트 Y-파라미터를 이용하여 계산할 수 있으며, 이 것이 모두 기준형 값과 동일할 경우, 트라이섹션 여 파기를 설계할 수 있다. 그러나 표 1 의 값은 대역폭 $\omega^{\prime}=1$ 을 갖는 일반적인 저역 통과 기준형 결합 행 렬 값이며, 대역 통과 기준형이 아니므로 저역 통과 기준형의 다중 포트 Y-파라미터는 결합 행렬을 이용 하여 아래와 같이 나타낼 수 있다 ${ }^{[1]}$.

$$
\mathrm{y}=j \omega \mathrm{I}+j \mathrm{M}+\mathrm{G}
$$

여기서, $\mathrm{y}$ 는 저역 통과 기준형의 어드미턴스 행렬이 며, $\mathrm{M}=\left[M_{i j}\right]$ 는 결합 행렬을 나타낸다. $\mathrm{G}$ 는 소스와 부하 노드를 제외한 모든 요소 값들이 영이 되는 종 단 컨덕턴스 행렬이고, $\mathrm{I}$ 는 단위 행렬이 된다.

식 (5)로부터 식 (8)까지 주어진 대역 통과 기준형 의 공진 주파수와 결합 계수는 주파수 변환을 이용 하여 아래와 같이 나타낼 수 있다 ${ }^{[2]}$.

$$
\begin{aligned}
& \widetilde{k_{i, j}}=\frac{B W}{\omega_{o}} M_{i j}(i \neq S, N \text { and } j \neq 1, L) \\
& \widetilde{k_{S, 1}}=\sqrt{\frac{B W}{\omega_{o}}} M_{S 1} \\
& \widetilde{k_{N, L}}=\sqrt{\frac{B W}{\omega_{o}}} M_{N L}
\end{aligned}
$$

표 2. 여파기의 결합 계수 및 공진 주파수

Table 2. Coupling coefficient and resonance frequency of filter.

\begin{tabular}{|c|c|c|c|}
\hline Parameter & Value & Parameter & Value \\
\hline$\widetilde{k_{S 1}}=\widetilde{k_{3 L}}$ & 0.2298 & $\widetilde{\omega_{r, 1}}=\widetilde{\omega_{r, 3}}$ & $2.435 \mathrm{GHz}$ \\
\hline$\widetilde{k_{12}} \widetilde{k_{23}}$ & 0.0463 & $\widetilde{\omega_{r, 2}}$ & $2.460 \mathrm{GHz}$ \\
\hline$\widetilde{k_{13}}$ & 0.0160 & - & - \\
\hline
\end{tabular}

$$
\begin{gathered}
\widetilde{\omega_{z, i}}=\omega_{o}\left(-\frac{M_{i i} B W}{2 \omega_{o}}+\sqrt{\left(\frac{M_{i i} B W}{2 \omega_{o}}\right)^{2}+1}\right), \\
i=1, \cdots, N
\end{gathered}
$$

식 (10)은 소스와 부하 노드를 포함한 $i$ 와 $j$ 에 대 해 정의된다. 여기서 $B W$ 와 $\omega_{o}$ 는 대역폭과 중심 주 파수를 나타낸다. 이것은 하측 및 상측 통과 대역 주 파수를 각각 $\omega_{1}, \omega_{2}$ 라고 정의하면, $B W=w_{2}-w_{1}$ 과 $w_{o}=\sqrt{w_{1} w_{2}}$ 로 나타낼 수 있다. 여기서 ? 은 기준 형 값으로 계산된 상수를 의미하며, 반면 식 (5) (7) 까지의 값은 주어진 구조에 대하여 $\mathrm{EM}$ 시뮬레이션 된 다중 포트 Y-파라미터로 계산된 값을 나타낸다. 표 2는 식 (10) 및 (11)에 의해 계산된 트라이섹션 여 파기의 공진 주파수와 결합 계수를 보였다.

\section{2-3 EM 시뮬레이션을 이용한 여파기 설계}

\section{2-3-1 여파기 구성 변수 추출 방법}

본 장에서는 2-2에서 설명한 다중 포트를 삽입하 여 EM 시뮬레이션한 결과들과 결합 행렬로부터 계 산된 결과들을 정합하여 여파기의 구성 변수들을 추 출하는 설계 방법을 제시한다.

여파기 설계 변수를 결정하기 위해 그림 1(b)와 같이 입 · 출력단, 첫 번째 공진기의 중앙 및 중앙공 진기의 개방 끝단에 포트들을 삽입하여 다중 포트 $\mathrm{Y}$-파라미터 EM 시뮬레이션을 수행한다. 수행된 다 중 포트 $\mathrm{EM}$ 시뮬레이션 결과로부터 Y-파라미터를 계산할 수 있다. 식 (5), (6) 및 (7)을 이용하여 계산한 결합 계수와 식 (8)을 이용하여 계산한 공진 주파수 는 여파기의 물리적 치수들의 함수가 된다. 계산된 물리적 치수는 대역 통과 기준형으로부터 유도된 식 (10) 및 (11)을 만족하는 값으로 조정된다. 본 논문에 서 제시한 그림 1(b)와 같은 여파기의 경우, 여파기 
의 대칭성에 의해 첫 번째 공진기와 두 번째 공진기 의 공진 주파수를 조정하면 된다. 조정되어야 할 공 진 주파수의 개수를 $n_{r}$ 로 정의하였을 때, 정규화된 공진 주파수 함수는 식 (12)와 같이 표현할 수 있다.

$$
\bar{\omega}_{i}(\mathrm{p})=\frac{\omega_{r, i}(\mathrm{p})}{\widetilde{\omega_{r, i}}} \quad i=1, \cdots, n_{r}
$$

여기서 -는 정규화된 것을 의미한다. 또한, 식 (12) 에서 모든 $\bar{\omega}_{i}(\mathrm{p})$ 는 설계 목표를 만족하는 물리적 치 수들에 대해 1이 되어야 한다. 또한, $\mathrm{p}$ 는 식 (13)처럼 물리적 치수의 집합으로 표현되는 벡터이다.

$$
\mathbf{p}=\left(p_{1}, p_{2}, \cdots, p_{N}\right)^{T}
$$

여기서, $N$ 는 선택한 물리적 치수의 개수이다. 유사 하게 조정되어야 할 결합량의 개수를 $n_{k}$ 로 정의하 였을 때, 정규화된 결합도 함수는 식 (14)로 표현할 수 있다.

$$
\bar{m}_{l}(\mathrm{p})=\frac{k_{i, j}(\mathrm{p})}{\widetilde{k_{i, j}}} \quad\left(l=1, \cdots, n_{k}\right)
$$

여기서, 모든 $\bar{m}_{l}(\mathrm{p})$ 역시 설계 목표를 만족하는 물 리적 치수들에 대해 1 이 되어야 한다. 조정하기 위 한 결합도의 개수는 여파기 회로와 관련이 있으며, 그림 1(a)에서 제시한 교차 결합 여파기의 경우, 독 립적인 결합도의 개수는 여파기 대칭성을 고려하면 세 개가 된다. 따라서 대칭성에 의해 $J_{S, 1}\left(k_{S, 1}\right), J_{1,2}$ $\left(k_{1,2}\right)$ 및 $J_{1,3}\left(k_{1,3}\right)$ 에 해당하는 인버터 값을 조정하 면 설계 목표를 충분히 만족할 수 있다. 식 (13) 및 (14)로부터 벡터 비용 함수(vector cost function)는

$$
\begin{aligned}
u(\mathrm{p}) & =\left(u_{1}, u_{2}, \cdots, u_{n_{r}+n_{k}}\right)^{T} \\
& =\left(\bar{\omega}_{1}, \bar{\omega}_{2}, \cdots \bar{\omega}_{n_{r}}, \bar{m}_{1}, \cdots \bar{m}_{n_{k}}\right)^{T}
\end{aligned}
$$

로 표현된다. 벡터 비용 함수를 조정하기 위한 물리 적 치수의 개수들을 식 (15)에 주어진 벡터 비용 함수 로 구성된 비용 함수 $u_{i}$ 의 개수와 동일하게 선택하 면, 즉 $N=n_{r}+n_{k}$, 물리적 치수 벡터 $\mathrm{p}$ 는 $u(p)=I$ 의 비선형 연립방정식의 해가 된다. 이 때 여파기의 초기 설계 치수 벡터를 식 (16)과 같이 정의하고

$$
\mathrm{p}_{o}=\left(p_{o, 1}, p_{o, 2}, \cdots, p_{o, N}\right)^{T}
$$

초기 물리적 치수들이 설계하고자 하는 치수에 근접하다고 가정하면, 물리적 치수의 미소 변화에 대해, $\mathrm{u}(\mathrm{p})$ 는 식 (17)과 같이 전개할 수 있다.

$$
\mathrm{u}\left(\mathrm{p}_{\mathrm{o}}+\Delta \mathrm{p}\right) \cong \mathrm{u}\left(\mathrm{p}_{\mathrm{o}}\right)+\mathrm{J} \cdot \Delta \mathrm{p}
$$

여기서 J는 식 (18)에서 표현한 자코비안 행렬식 (Jacobian matrix)이며, 물리적 치수들의 미소 변화에 대해 근사적으로 상수 행렬이 된다.

$$
\mathbf{J}=\left(\begin{array}{cccc}
\frac{\partial u_{1}}{\partial p_{1}} & \cdots & \cdots & \frac{\partial u_{1}}{\partial p_{N}} \\
\vdots & \ddots & \vdots \\
\vdots & \ddots & \vdots \\
\frac{\partial u_{N}}{\partial p_{1}} & \cdots & \cdots & \frac{\partial u_{N}}{\partial p_{N}}
\end{array}\right)
$$

구하고자 하는 물리적 치수 벡터 $\mathrm{p}$ 가 설계값에 근접할 경우, $\mathrm{u}(\mathrm{p})$ 의 모든 요소들은 1 이 된다. 따라 서 $\mathrm{p}$ 는 식 (17)에서, 아래와 같이 얻어진다.

$$
\mathrm{p} \cong \mathrm{p}_{\mathrm{o}}+\mathrm{J}^{-1} \xi
$$

여기서, 벡터 $\xi$ 는 식 (20)과 같이 정의된다.

$$
\xi=\left(1-u_{1}\left(\mathrm{p}_{o}\right), 1-u_{2}\left(\mathrm{p}_{o}\right), \cdots, 1-u_{N}\left(\mathrm{p}_{o}\right)\right)^{T}
$$

따라서 초기치가 근접하다면, 식 (19)를 계산하여 최종 설계치를 반복 없이 계산할 수 있다. 만일 초기 치가 다소 근접하지 않다면 식 (19)를 반복하여 최종 설계치를 얻게 된다. 이것은 수치 해석적인 NewtonRaphson 방법과 동일하다.

\section{2-3-2 트라이섹션 여파기 구성 설계값 추출}

본 절에서는 앞서 설명한 여파기 설계 방법을 트 라이섹션 여파기에 적용하였다. 초기 설계 치수를 구하기 위하여 트라이섹션 여파기를 그림 4(a) 및 4(b)와 같이 개별공진기로 분해하여 계산하면, EM 시뮬레이션 설계 시간을 크게 단축할 수 있다. 이 초 기 설계 치수는 여파기의 최종 설계 치수에 상당히 근접하기 때문에, 이 치수들을 이용하여 전체 여파 기를 구성하고, EM 시뮬레이션하면 식 (19)를 이용 하여 용이하게 최종 설계 치수를 얻게 된다. 또한, 전체 여파기 $\mathrm{EM}$ 시뮬레이션 설계시간을 크게 단축 할 수 있다.

본 논문에서 제안한 그림 1(a)의 트라이섹션 여파 
기는 표 2 와 같이 3 개의 결합 계수와 2 개의 공진 주 파수를 가지며, 각각의 결합 계수와 공진 주파수들 은 물리적 치수 조정을 통하여 맞춰야 할 것이다. 물 리적 치수들은 공진 주파수 조정을 위하여 $l_{1}$ 과 $l_{2}$ 길이를 선정하였으며, 결합 계수 조정을 위해 결합 간극 $s_{01}, s_{12}$ 및 교차 결합 길이 $l_{c}$ 를 선택하였다. 또 한, 결합 선로의 선로폭은 제작의 편의를 위해 50 옴 전송 선로의 폭과 동일하게 선정하였다. 따라서 트 라이섹션 여파기의 물리적 치수 벡터는 $\mathrm{p}=\left(l_{1}, l_{2}\right.$, $\left.s_{01}, s_{12}, l_{c}\right)^{T}$ 이며, 이에 대한 벡터 비용 함수는 $u(\mathrm{p})=$ $\left(\bar{\omega}_{1}, \bar{\omega}_{2}, \bar{m}_{1}, \bar{m}_{2}, \bar{m}_{3}\right)^{T}$ 로 표현된다. 여기서 $\bar{\omega}_{1}$ 은 입 력공진기의 정규화된 공진 주파수 벡터 비용 함수이 며, $\bar{\omega}_{2}$ 는 중앙공진기의 정규화된 공진 주파수 벡터 비용 함수를 의미한다. 또한, $\bar{m}_{n}$ 은 정규화된 결합 계수이며, 아래첨자 1 은 그림 1(a)의 정규화된 $k_{S, 1}, 2$ 는 정규화된 $k_{1,2}$, 3 은 정규화된 $k_{1,3}$ 를 나타낸다. 그 림 4(a)와 같이 분해된 중앙공진기에 대한 물리적 치 수 벡터는 $\mathrm{p}_{1}=\left(l_{2}, s_{12}, l_{c}\right)^{T}$ 이며, 이에 대응하는 비용 함수는 $u\left(\mathrm{p}_{1}\right)=\left(\bar{\omega}_{2}, \bar{m}_{2}, \bar{m}_{3}\right)^{T}$ 가 된다. 그림 $4(\mathrm{~b})$ 에 보인 분해된 입력공진기에서 중앙공진기 $l_{2}$ 를 고정 하면, $\mathrm{p}_{2}=\left(l_{1}, s_{01}\right)^{T}, u\left(\mathrm{p}_{2}\right)=\left(\bar{\omega}_{1}, \bar{m}_{1}\right)^{T}$ 가 된다.

그림 4(a) 및 4(b)에서 제시한 중앙공진기와 입력 공진기의 $\mathrm{EM}$ 시뮬레이션을 위한 마이크로스트립 기판의 두께는 $25 \mathrm{mil}$, 유전상수는 9.9로 설정하였다.

$\mathrm{ADS}$ 의 Momentum에서 시뮬레이션을 수행할 경 우 $^{[11]}$, 해석된 결과값의 신뢰도를 높이기 위해 시뮬 레이션을 수행하는 mesh 주파수는 여파기 중심 주 파수의 두 배인 $5 \mathrm{GHz}$ 로 설정하였으며, mesh 밀도는 mesh 주파수의 파장 대비 80 개의 셀을 가지며, 곡면 의 해석 정확도는 $10^{\circ}$ 로 설정하였다.

중앙공진기의 물리적 변수를 추출하기 위해 중앙 공진기의 $\mathrm{p}_{1}$ 벡터로 정의한 $l_{2}, s_{12}$ 및 $l_{c}$ 에 대한 초 기값이 필요하다. 입력공진기의 길이 초기값인 $l_{1}^{I C}$ 은 결합이 없는 단일 전송 선로에 대해 $1 / 4$ 파장에 해당하는 $471.5 \mathrm{mil}$ 로 선정하였다. 같은 방법으로 중 앙공진기의 길이 초기값 $l_{2}^{I C}$ 는 $465.8 \mathrm{mil}$ 로 선정하였 다. 길이 차는 표 2 의 공진 주파수 차에 따른 것이다. $l_{c}^{I C}$ 은 입력공진기 사이의 교차 결합을 허용하기 위 해 중앙공진기 길이의 $1 / 2$ 로 설정하였다. 간극 $s_{12}^{I C}$ 는

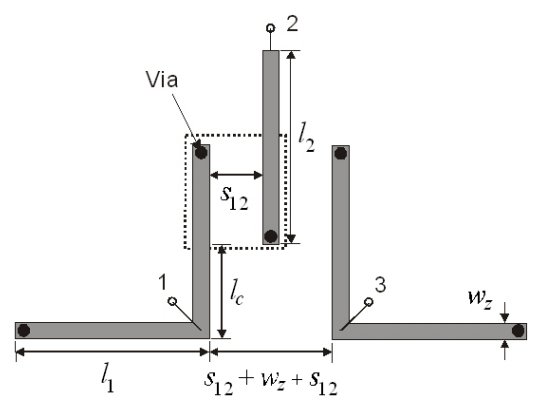

(a) 중앙공진기

(a) Center resonator

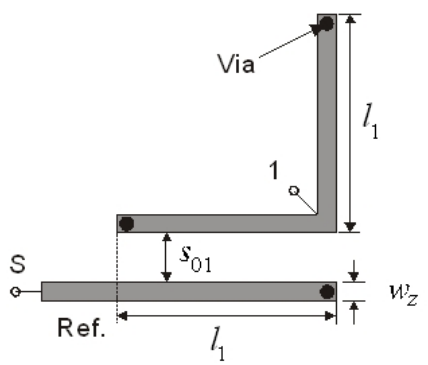

(b) 입력공진기

(b) Outer resonator

그림 4. 트라이섹션 여파기의 개별공진기 분해

Fig. 4. Individual resonator decomposition of trisection filter.

$38 \mathrm{mil}$ 를 선정하였다. 이것은 그림 4(a)의 점선으로 표시된 사각형에 위치한 결합 전송 선로에 대해 Y파라미터를 계산하고, 식 (5)로 계산된 값이 $\widetilde{k_{1,2}}$ 가 되도록 설정한 것이다. 따라서 이들은 초기 물리적 치수 벡터

$$
\mathrm{p}_{o 1}=\left(l_{2}^{I C}, s_{12}^{I C}, l_{c}^{I C}\right)^{T}
$$

의 벡터 요소가 된다. 이를 이용하면 설계 치수 $\mathrm{p}_{1}$ 은 식 (19)로부터 구할 수 있다. 이것은 ADS 상에서 계 산 가능하며, 표 3 에 계산 결과를 보였다. 그림 5 는 중앙공진기에서 물리적 치수 변화 그림 4(a)로 부터 얻어진 설계 치수 $\mathrm{p}_{1}$ 로 정규화 후 이에 대한 비용 함 수들의 변화를 보였다. 그림 5 에서와 같이 선정한 설계 치수 근처에서 비용 함수들이 선형임을 확인하 였다.

그림 5는 그림 4(a)로 부터 얻어진 설계 치수 $\mathrm{p}_{1}$ 으 로 정규화한 후 이에 대한 비용 함수들의 변화를 보 였다. 그림 5 에서와 같이 선정한 설계 치수 근처에 


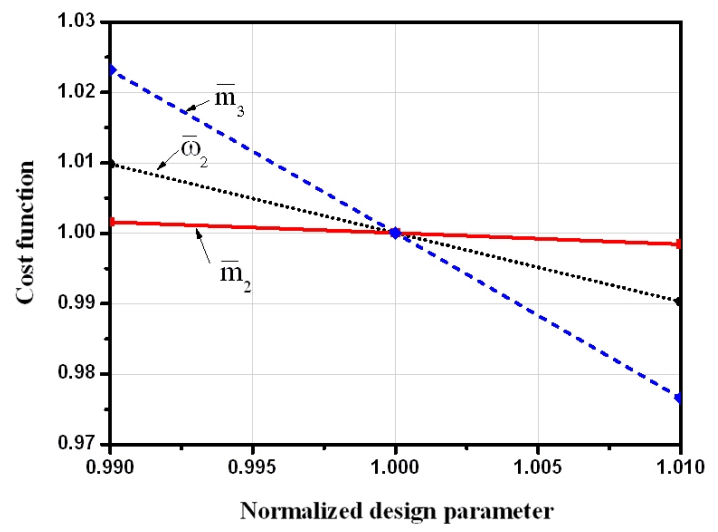

그림 5. 중앙공진기에서 정규화된 물리적 치수 변화 에 대한 비용 함수들의 결과(기준값: 표 3 의 $\left.l_{2}, s_{12}, l_{c}\right)$

Fig. 5. Results of the cost function for a change of dimension at the center resonator(reference value: $l_{2}, s_{12}, l_{c}$ of Table 3 ).

표 3. 개별공진기의 치수 설계값

Table 3. Design parameters of individual resonators.

\begin{tabular}{|c|c|c|c|}
\hline 길이 & 값[mil] & 간격 & 값[mil] \\
\hline$l_{1}$ & 477.264 & $s_{01}$ & 10.186 \\
\hline$l_{2}$ & 466.171 & $s_{12}$ & 36.540 \\
\hline$l_{c}$ & 313.158 & - & - \\
\hline
\end{tabular}

서 비용 함수들이 선형임을 확인할 수 있다.

그림 4(b)는 입력공진기를 구성하는 물리적 치수 벡터 $\mathrm{p}_{2}=\left(l_{1}, s_{01}\right)^{T}$ 를 구하기 위한 구성도이다. 앞서 $l_{1}^{I C}$ 는 이미 $471.5 \mathrm{mil}$ 로 선정하였다. 간극 $s_{01}^{I C}$ 는 38 mil로 두고, 그림 4(b)에서 계산된 2-포트 Y-파라미 터를 이용하여 $u\left(\mathrm{p}_{2}\right)=\left(\bar{\omega}_{1}, \bar{m}_{1}\right)^{T}$ 를 계산하고, 이것 이 $(1,1)^{T}$ 을 만족하도록 식 (19)를 이용하여 반복하 였다. 이렇게 얻어진 입력공진기의 물리적 치수를 표 3에 나타내었다.

여파기 초기 치수 결정을 위해 개별공진기로 분 해하여 얻어진 결과는 $\mathrm{EM}$ 시뮬레이션 시간을 단축 하여 계산되었으나, 비인접 결합을 고려하지 않아 전체 여파기의 특성과 차이가 발생하였다. 따라서 표 3 의 물리적 치수 5 개를 초기값으로 설정하여 그 림 1(a)의 전체 여파기에 대해 다중 포트 EM 시뮬레 이션을 수행하였다. 이 경우 차원만 늘어나게 되고, 방법적으로는 개별공진기 계산과 동일하다. 2 회의
표 4. 여파기의 치수 설계값

Table 4. Design parameters of filter.

\begin{tabular}{|c|c|c|c|}
\hline 길이 & 값[mil] & 간격 & 값[mil] \\
\hline$l_{1}$ & 478.057 & $s_{01}$ & 10.053 \\
\hline$l_{2}$ & 466.432 & $s_{12}$ & 35.778 \\
\hline$l_{c}$ & 321.859 & - & - \\
\hline
\end{tabular}

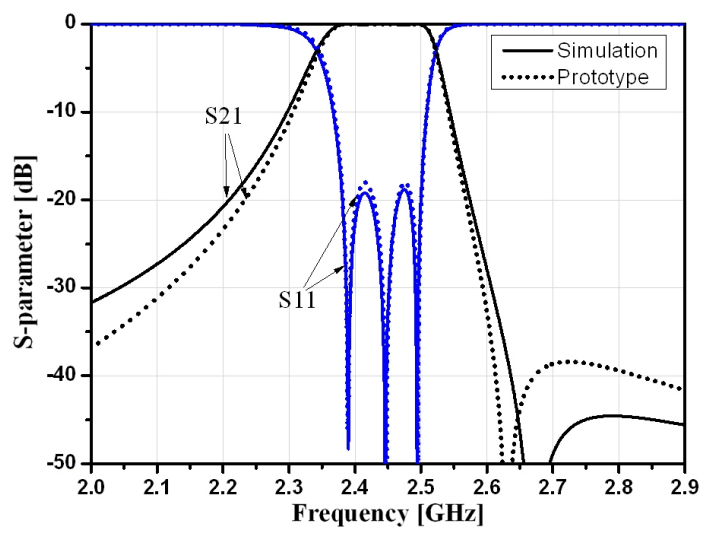

그림 6. 트라이섹션 여파기의 EM 시뮬레이션 결과 Fig. 6. EM simulation results of trisection filter.

EM 시뮬레이션으로 얻어진 물리적 치수는 표 4와 같으며, 이들의 결과에서 얻어진 여파기의 주파수 응답 특성은 그림 6 과 같다.

그림 6에서 통과 대역의 리플 특성은 결합 행렬로 부터 구한 기준형 여파기의 특성과 유사하나, 상측 전달 영점의 위치에서 차이가 발생하였다. 전달 영 점의 위치에 영향을 주는 요소를 확인하기 위해, 다 중 포트 $\mathrm{EM}$ 시뮬레이션으로부터 얻어진 Y-파라미 터를 이용하여 결합 행렬을 표 5 와 같이 구하였다.

표 5의 결합 행렬은 이론적으로 계산한 표 1 의 결 과와 차이가 발생하였다. 이와 같이 원하지 않는 비

표 5. EM 시뮬레이션으로 계산된 결합 행렬

Table 5. Coupling matrix calculated by EM simulation.

\begin{tabular}{|c|c|c|c|c|c|}
\hline & $S$ & 1 & 2 & 3 & $L$ \\
\hline$S$ & 0 & 1.027 & $\mathbf{0 . 0 0 4}$ & $\mathbf{0 . 0 0 8}$ & $\mathbf{0 . 0 0 3}$ \\
\hline 1 & 1.027 & 0.073 & 0.924 & 0.320 & $\mathbf{0 . 0 0 8}$ \\
\hline 2 & $\mathbf{0 . 0 0 4}$ & 0.924 & -0.328 & 0.924 & $\mathbf{0 . 0 0 4}$ \\
\hline 3 & $\mathbf{0 . 0 0 8}$ & 0.320 & 0.924 & 0.073 & 1.027 \\
\hline$L$ & $\mathbf{0 . 0 0 3}$ & $\mathbf{0 . 0 0 8}$ & $\mathbf{0 . 0 0 4}$ & 1.027 & 0 \\
\hline
\end{tabular}


인접 결합이 존재할 경우, 여파기의 결합 행렬은 이 론적인 결합 행렬과 차이가 발생하게 된다.

\section{2-3-3 다중 결합도를 고려한 여파기 최적화}

표 5 에서 확인한 바와 같이 미지의 작은 비인접 공진기간 결합이 발생하는 것을 알 수 있으며, 이것 들을 0 으로 만들어 원하는 여파기에 가깝게 할 필요 가 있다. 그러나 이것들의 물리적 치수에 대한 의존 도는 알 수 없으며, 이것들을 0 으로 만드는 방법 또 한 잘 정립되어 있지 않다. 따라서 이러한 비인접 공 진기간의 결합을 포함하여 여파기의 물리적 치수가 기준형에 근접한 여파기 응답 특성을 갖도록 조정될 필요가 있다. 이를 위해 가장 효과적인 방법은 최적 화 일 것이다. 그러나 여파기를 구성하는 개별 치수 들의 직접적인 최적화는 최근의 컴퓨터 환경에서도 매우 많은 계산 시간이 요구되며, 그 결과의 수렴도 보장할 수 없다. 이에 본 논문에서는 먼저 1 차 설계 된 여파기의 각 물리적 치수에 대하여 최적화 없이 일정 범위 내에서 스윕한 다중 포트 $S$-파라미터를 이용하여 최적화하는 방법을 선정하였다. 이 스윕된 다중 포트 $S$-파라미터를 $\mathrm{ADS}$ 의 $\mathrm{DAC}(\mathrm{DataAccess}$ Component)에 이동시키고, 회로 영역에서 최적화를 수행하였다 ${ }^{[1]}$. 이를 통해 비교적 신속하게 최종 설 계 치수를 도출할 수 있었다. 표 6 은 최적화를 통해 얻어진 여파기의 최종 설계 치수이며, 표 6의 설계 치수를 갖는 여파기의 주파수 응답 특성을 그림 7에 보였다. 표 7은 최적화를 수행하여 얻어진 다중 포 트 Y-파라미터로부터 구한 결합 행렬로써 표 5의 결 합 행렬과 비교하여 각 행렬의 요소 값이 변환된 것 을 확인할 수 있다. 이는 앞서의 설계들에서 고려하 지 못한 다중 결합의 존재에 대한 최적화의 결과로 사료된다.

최적화의 결과로 계산된 표 7의 결합 행렬은 표 1

표 6. 최적화 수행 후 여파기의 치수 설계값

Table 6. Optimization results of design parameters.

\begin{tabular}{|c|c|c|c|}
\hline 길이 & 값[mil] & 간격 & 값 [mil] \\
\hline$l_{1}$ & 477.76 & $s_{01}$ & 10.130 \\
\hline$l_{2}$ & 466.143 & $s_{12}$ & 31.274 \\
\hline$l_{c}$ & 338.523 & - & - \\
\hline
\end{tabular}

표 7. 최적화 수행 후 결합 행렬

Table 7. Optimization results of coupling matrix.

\begin{tabular}{|c|c|c|c|c|c|}
\hline & $S$ & 1 & 2 & 3 & $L$ \\
\hline$S$ & 0 & 1.023 & $\mathbf{0 . 0 0 4}$ & $\mathbf{0 . 0 0 9}$ & $\mathbf{0 . 0 0 3}$ \\
\hline 1 & 1.023 & 0.057 & 0.909 & 0.369 & $\mathbf{0 . 0 0 9}$ \\
\hline 2 & $\mathbf{0 . 0 0 4}$ & 0.909 & -0.355 & 0.909 & $\mathbf{0 . 0 0 4}$ \\
\hline 3 & $\mathbf{0 . 0 0 9}$ & 0.369 & 0.909 & 0.057 & 1.023 \\
\hline$L$ & $\mathbf{0 . 0 0 3}$ & $\mathbf{0 . 0 0 9}$ & $\mathbf{0 . 0 0 4}$ & 1.023 & 0 \\
\hline
\end{tabular}

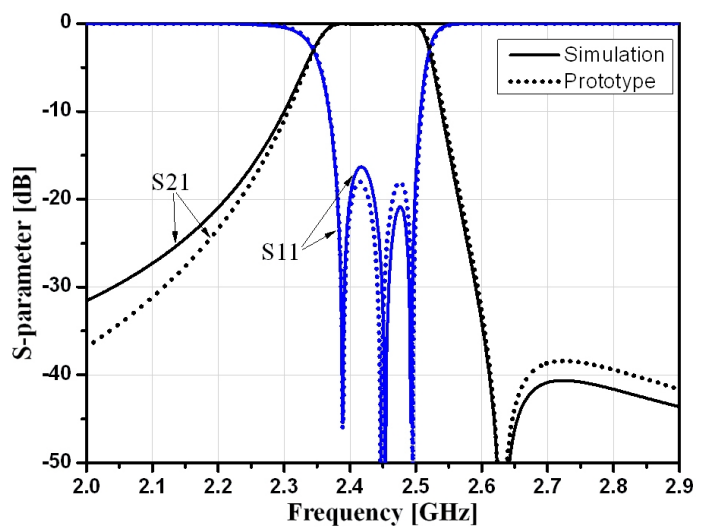

그림 7. 트라이섹션 여파기의 최적화 결과

Fig. 7. Optimization results of trisection filter.

의 이상적인 결합 행렬과 차이가 있지만, 최적화를 통해 그림 7에서와 같이 기준형 여파기의 응답 특성 과 유사하게 만들 수 있었다. 그러나 여파기 구조의 형상에 의해 필연적으로 발생하는 불필요한 결합을 제거할 수 없었다. 그래서 최적화된 결합 행렬이 기 준형 여파기의 결합 행렬과 같게 되기 위해서는 불 필요한 다중 결합을 제거할 수 있는 여파기 구조가 필요할 것으로 사료된다.

\section{III. 여파기 제작 및 측정}

그림 8은 최종 최적화 후 획득한 물리적 치수로 제작한 여파기이며, 제작에 사용된 기판은 Taconic 사의 $\mathrm{CER} 10^{[12]}$ 으로 유전율 9.9 와 두께 $25 \mathrm{mil}$ 을 갖 는다.

그림 9의 굵은 실선은 제작된 여파기의 주파수 응 답 특성에 대한 측정 결과이다. 여파기의 측정 결과 를 보면 그림 7의 최종 시뮬레이션(그림 9의 점선)과 달리 중심 주파수가 상향 이동하고 대역폭이 다소 넓 


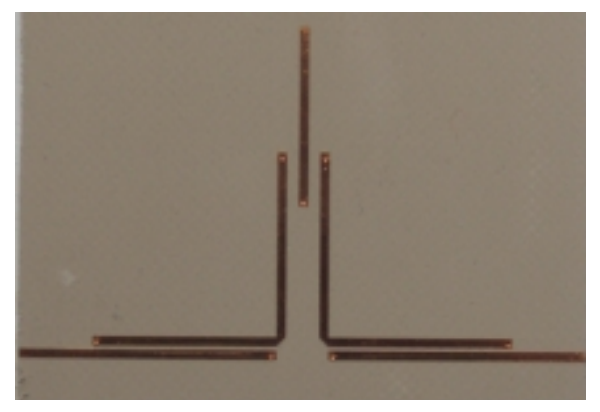

그림 8. 제작된 인터디지털 트라이섹션 대역 통과 여 파기 $(1,500 \mathrm{mil} \times 870 \mathrm{mil})$

Fig. 8. Fabricated interdigital trisection band-pass filter (1,500 mil $\times 870$ mil).

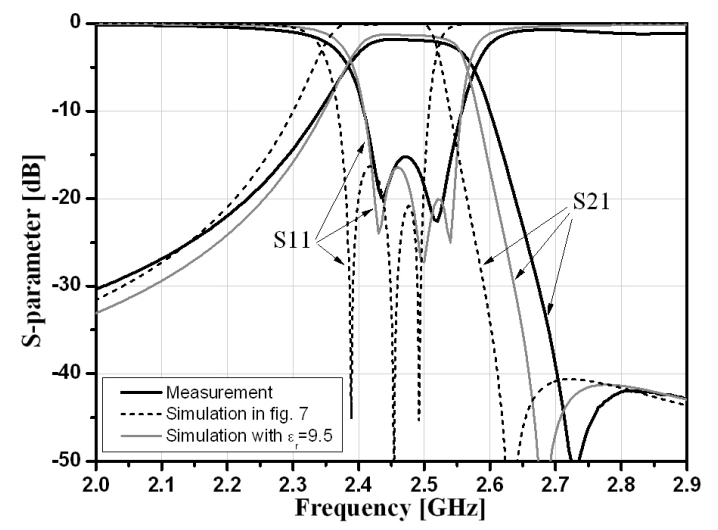

그림 9. 트라이섹션 대역 통과 여파기의 시뮬레이션 및 측정 결과

Fig. 9. Simulation and measurement results of trisection band-pass filter.

어졌다. 이러한 특성 변화를 확인하기 위해 CER 10 의 기판 특성을 측정한 결과, 유전율이 9.5 임을 확인 하였다. 그림 9의 얇은 실선은 유전율을 9.5 로 변경 하고, 유전체 손실 및 도체 두께를 포함한 여파기 시 뮬레이션 결과이다. 시뮬레이션 결과와 측정한 여파 기의 응답 특성 차이는 여파기 제작에서 발생한 제 작공차에 의한 것으로 판단되며, 제작된 기판의 물 성이 설계와 정확히 일치하지 않기 때문인 것으로 사료된다.

\section{$\mathrm{IV}$. 결 론}

본 논문에서는 $\mathrm{EM}$ 시뮬레이션에 기초한 새로운 여파기 설계 방법을 제안하였으며, 제안한 설계 방
법의 타당성을 검증하기 위해 교차 결합을 갖는 트 라이섹션 여파기를 설계, 제작하였다. 트라이섹션 여파기의 결합 행렬을 구하였으며, 이를 여파기 기 준형 등가 회로에 정합하였다. 여파기의 물리적 치 수를 구하기 위해 여파기에 다중 포트를 삽입하고, $\mathrm{EM}$ 시뮬레이션을 수행하여 Y-파라미터를 구하였다. 계산된 Y-파라미터를 이용하여 여파기의 물리적 치 수들에 대한 자코비안 행렬을 구하고, 이들로부터 여파기 설계 치수들을 결정하였다. 또한, 불필요한 교차 결합을 확인하였으며, 불필요한 교차 결합이 존재하더라도 기준형 여파기의 특성과 동일한 주파 수 응답 특성을 만족하는 여파기를 최적화를 통해 설계할 수 있었으며, 트라이섹션 여파기를 제작하여 여파기의 설계 방법을 검증하였다. 본 논문에서 제 안한 설계 방법을 적용하면, 간단한 구조를 갖는 평 행결합 선로 여파기뿐만 아니라 다중결합을 갖는 여 파기 설계에도 적용할 수 있을 것으로 사료된다.

\section{참 고 문 헌}

[1] R. J. Cameron, C. M. Kudsia, and R. R. Mansour, Microwave Filters for Communication Systems, John Wiley \& Sons Inc., 2007.

[2] D. Swanson, G. Macchiarella, "Microwave filter design by synthesis and optimization", IEEE Microwave Magazine, vol. 8, no. 2, pp. 55-69, Apr. 2007.

[3] M. Dishal, "Alignment and adjustment of synchronously tuned multiple-resonant-circuit filters", in Proc. IRE, vol. 39, pp. 1448-1455, Nov. 1951.

[4] R. Rhea, "EM enables classic filter technique", Microwave Journal, vol. 50, no. 2, pp. 138-145, Feb. 2007.

[5] D. G. Swanson, "Narrowband microwave filter design", IEEE Microwave Magazine, vol. 8, no. 5, pp. 105-114, Oct. 2007.

[6] J. S. Hong, M. J. Lancaster, Microstrip Filters for RF/Microwave Applications, John Wiley \& Sons Inc., 2001.

[7] S. Koziel, Q. S. Cheng, and J. W. Bandler, "Space mapping", IEEE Microwave Magazine, vol. 9, no. 6, pp. 105-122, Dec. 2008. 
[8] J. W. Bandler, R. M. Biernacki, S. H. Chen, D. G. Swanson, Jr., and S. Ye, "Microstrip filter design using direct EM field simulation", IEEE Trans. Microw. Theory Tech., vol. 42, no. 7, pp. 1353-1359, Jul. 1994.

[9] 양승식, 염경환, "무 손실 2-포트 회로의 인버터 를 사용한 등가 회로 및 응용", 한국전자파학회 논문지, 19(7), pp. 761-770, 2008년 7월.
김 소 수

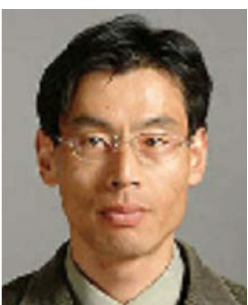

1993년 2월: 경북대학교 전자공학 과 (공학사)

1996년 2월: 경북대학교 전자공학 과 (공학석사)

1996년 1월 현재: 국방과학연구소 2007년 3월 현재: 충남대학교 전 파공학과 박사과정

[주 관심분야] 초고주파 송수신시스템 설계
[10] G. L. Matthaei, L. Young, and E. M. T. Jones, Microwave Filters, Impedance-Matching Networks, and Coupling Structures, New York: McGrawHill, 1964.

[11] Advanced Design System 2001 Momentum, Agilent Technologies, 2001.

[12] ORCER Cer 10, Organic-Ceramic DK-10 Laminate, Taconic, 2010.

염 경 환

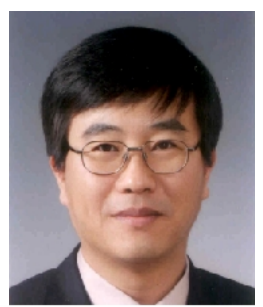

1976년 1980년: 서울대학교 전자 공학과 (공학사)

1980년 1982년: 한국과학기술원 전 기 및 전자과 (공학석사)

1982년 1988년: 한국과학기술원 전 기 및 전자과 (공학박사)

1988년 3월: 금성전기(주) 소재부품

연구소 선임연구원 (MIC팀 팀장)

1990년 3월: 금성전기(주) 소재부품연구소 책임연구원

1991년 5월: 금성정밀(주) 기술연구소 연구1실 책임연구원 1991년 8월: (주) LTI

1995년 10월 현재: 충남대학교 전파공학과 교수

[주 관심분야] 초고주파 능동 회로 및 시스템, MMIC 설계 